\title{
Perihilar Bile Duct Cancer pT3 TNM
}

\section{Finding v8}

National Cancer Institute

\section{Source}

National Cancer Institute. Perihilar Bile Duct Cancer pT3 TNM Finding v8. NCI Thesaurus.

Code C134729.

Perihilar bile duct cancer with tumor invading unilateral branches of the portal vein or hepatic artery. (from AJCC 8th Ed.) 